Andrea Ronchi ${ }^{a}$, Christopher P. Ouellette ${ }^{a}$, Asuncion Mejías, Douglas Salamon, Amy Leber, Lorenza Pugni, Fabio Mosca and Pablo J. Sánchez*

\title{
Detection of cytomegalovirus in saliva from infants undergoing sepsis evaluation in the neonatal intensive care unit: the VIRIoN-C study
}

https://doi.org/10.1515/jpm-2018-0021

Received January 14, 2018; accepted April 11, 2018; previously published online May 16, 2018

\section{Abstract}

Objective: To determine the frequency of detection of cytomegalovirus (CMV) among infants evaluated for lateonset sepsis in the neonatal intensive care unit (NICU).

Methods: This study was a prospective cohort study.

Results: During the 13-month study, 84 infants underwent 116 sepsis evaluations, and CMV DNA was detected in saliva in three (4\%) infants (median: gestational age 28 weeks, birth weight $950 \mathrm{~g})$, representing $5 \%(\mathrm{n}=6)$ of all sepsis evaluations. One infant had CMV DNA detected in saliva in all four sepsis evaluations. Two infants had acquired CMV infection, while the timing of CMV acquisition could not be determined in one infant. Two of the three infants had concomitant Gram-negative bacteremia and urinary tract infections (UTIs), two developed severe bronchopulmonary dysplasia (BPD) and none died.

Conclusion: Detection of CMV DNA in saliva occurred in $4 \%$ of infants and $5 \%$ of sepsis evaluations. Persistence of
CMV DNA shedding in saliva made attribution of clinical illness difficult to ascertain.

Keywords: acquired cytomegalovirus infection; cytomegalovirus infection; neonatal sepsis.

\section{Introduction}

Postnatal detection of cytomegalovirus (CMV) among infants in the neonatal intensive care unit (NICU) has been associated with a sepsis-like syndrome as well as bronchopulmonary dysplasia (BPD), necrotizing enterocolitis and even death [1-6]. Acquisition of CMV by infants in the NICU also results in asymptomatic infection and usually occurs by ingestion of unpasteurized human milk [7]. However, the incidence of CMV infection among infants in the NICU who are evaluated for possible late-onset sepsis is not known. Therefore, the objective of this study was to determine the frequency and potential impact of CMV detection among infants who were evaluated for late-onset sepsis in a Level

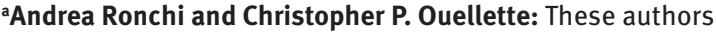
contributed equally to this work.

*Corresponding author: Pablo J. Sánchez, MD, Department of Pediatrics, Divisions of Neonatal-Perinatal Medicine and Pediatric Infectious Diseases, University of Texas Southwestern Medical Center, Dallas, TX, USA; Department of Pediatrics, Divisions of Neonatology and Pediatric Infectious Diseases, Nationwide Children's Hospital - The Ohio State University College of Medicine, Columbus, OH, USA; Center for Perinatal Research, The Research Institute at Nationwide Children's Hospital, Columbus, $\mathrm{OH}$, USA; and Nationwide Children's Hospital - The Ohio State University, 700 Children's Drive, RB3, WB5245, Columbus, OH 43205-2664, USA, Tel.: +614-355-6638,

E-mail: Pablo.Sanchez@nationwidechildrens.org

Andrea Ronchi: Neonatal Intensive Care Unit, Department of Clinical Sciences and Community Health, Fondazione IRCCS Ca' Granda Ospedale Maggiore Policlinico, Università degli Studi di Milano, Milan, Italy; and Department of Pediatrics,
}

Divisions of Neonatal-Perinatal Medicine and Pediatric Infectious Diseases, University of Texas Southwestern Medical Center, Dallas, TX, USA

Christopher P. Ouellette: Department of Pediatrics, Division of Pediatric Infectious Diseases, Nationwide Children's Hospital - The Ohio State University College of Medicine, Columbus, OH, USA

Asuncion Mejías: Department of Pediatrics, Division of Pediatric Infectious Diseases, Nationwide Children's Hospital - The Ohio State University College of Medicine, Columbus, OH, USA; and Center for Vaccines and Immunity, The Research Institute at Nationwide Children's Hospital, Columbus, OH, USA Douglas Salamon and Amy Leber: Department of Laboratory Medicine, Nationwide Children's Hospital, Columbus, $\mathrm{OH}$, USA Lorenza Pugni and Fabio Mosca: Neonatal Intensive Care Unit, Department of Clinical Sciences and Community Health, Fondazione IRCCS Ca' Granda Ospedale Maggiore Policlinico, Università degli Studi di Milano, Milan, Italy 
III NICU at Parkland Memorial Hospital (PMH), Dallas, TX, USA.

\section{Materials and methods}

\section{Setting}

This was a prospective cohort study of all infants who were hospitalized in the NICU at PMH from January 15, 2012 to January 31, 2013 and were enrolled in the viral respiratory infections in the neonatal intensive care unit (VIRIoN-I) study that determined the frequency and role of respiratory viral infections, as detected by polymerase chain reaction (PCR) testing, among infants who were evaluated for possible late-onset sepsis [8]. The PMH NICU is a 90-bed, Level IIIC, predominantly inborn unit with approximately 1400 admissions annually. The unit is staffed by neonatologists from the University of Texas Southwestern Medical Center, along with neonatology fellows, neonatal nurse practitioners and pediatric residents. Infants with surgical conditions were cared for in the NICU pre- and postsurgery. Infants who required extracorporeal membrane oxygenation or cardiac surgery other than patent ductus arteriosus ligation were transferred to Children's Medical Center Dallas.

Mothers had unlimited access except in the high acuity area where visiting was discouraged from 9 AM to noon when daily patient rounds were held. While siblings $\geq 12$ years of age could visit anytime with a parent, siblings $<12$ years of age only visited with a parent twice a week under the supervision of a child life specialist. Provision of either fresh or frozen maternal milk was encouraged, but there was no donor human milk used during the study period. In addition, there was no use of colostrum or human milk for oral hygiene. A leukoreduction transfusion policy was used during the study period and both CMV seropositive and seronegative red blood cell units were utilized after irradiation [9].

\section{Patients}

Infants were eligible if they were inborn, had never been discharged to home, were evaluated for possible late-onset sepsis and antibiotic therapy was initiated at $>72 \mathrm{~h}$ of age. Evaluation for suspected sepsis was at the discretion of the attending neonatologist, as were decisions regarding the use and duration of specific antimicrobial agents for all clinical scenarios. Eligible infants were identified by daily review of all antibiotics provided by the NICU pharmacists. Infants who received antibiotics for only superficial skin or surgical site infection were excluded.

After obtaining an informed consent from parents/guardians, the enrolled infants had saliva swabs obtained for CMV detection within $72 \mathrm{~h}$ of initiation of antibiotic therapy [8]. Their medical records were reviewed for pertinent maternal and infant demographic, clinical, radiographic and laboratory data until discharge from the NICU. Congenital CMV infection was defined as detection of CMV from a clinical specimen before 21 days of age, while infants with acquired CMV infection had an initial negative CMV DNA PCR test but subsequently had CMV DNA detected in saliva after 21 days of age. Clinical and laboratory definitions and abnormalities were determined as previously reported [8]. Briefly, hypothermia was defined as axillary temperature $<36^{\circ} \mathrm{C}$ [10], while fever was temperature $\geq 38^{\circ} \mathrm{C}$ [11]. Diagnosis of a urinary tract infection (UTI) was based on the neonatologist's assessment in the medical record, bacterial growth on urine obtained by either suprapubic bladder aspiration (any growth of Gram-negative bacilli; >50,000 colony-forming units (CFU)/mL Gram-positive cocci) or catheterization $(>50,000 \mathrm{CFU} / \mathrm{mL})$ and/or receipt of $\geq 7$ days of appropriate antibiotic therapy. Thrombocytopenia was $<100,000 / \mathrm{mm}^{3}$ [12]. BPD was determined by the National Institutes of Health severity-based consensus definition [13]. The study was approved by the Institutional Review Board of the University of Texas Southwestern Medical Center.

\section{Saliva specimens}

Saliva swabs were stored at $-80^{\circ} \mathrm{C}$, and subsequently processed for CMV by quantitative PCR (Virology Laboratory, Nationwide Children's Hospital, Columbus, OH, USA) as previously described [14].

\section{Statistical analyses}

For descriptive statistics, normality of continuous covariates was assessed first using the Kolmogorov-Smirnov test. For normally distributed data, means with standard deviation (SD) were derived for descriptive statistics (e.g. patient demographics and characteristics), while median values with interquartile range (IQR) were calculated for non-normally distributed data. Proportions were calculated for categorical data. Bivariate analyses were performed to determine the association between the dependent variable (presence of virus) and independent covariates using $t$-tests for normally distributed data and the Mann-Whitney $U$-test for nonparametric data. Chi-square or Fisher's exact tests were used for categorical variables as appropriate. A two-tailed P-value $<0.05$ was considered to be statistically significant. The Bonferroni correction was used to correct for multiple testing when groups that included multiple parameters were analyzed, with the corresponding P-values representing the adjusted values.

\section{Results}

During the 13-month study period, 84 (91\%) of 92 eligible infants were enrolled (Figure 1). The mothers/legal guardians of five infants declined enrollment in the study, while three infants were missed. The majority of mothers were Hispanic and delivered their infants by cesarean section (Table 1); four (4.7\%) mothers were infected with the human immunodeficiency virus but the infants were uninfected. The infants were mostly male $(51,61 \%)$, preterm (81\% <37 weeks' gestation; 66\% <34 weeks' gestation) and of low birth weight ( $67 \%<2000 \mathrm{~g}$ birth weight; 57\% $<1500$ g; 29\% <1000 g; Table 1). The onset of clinical signs 


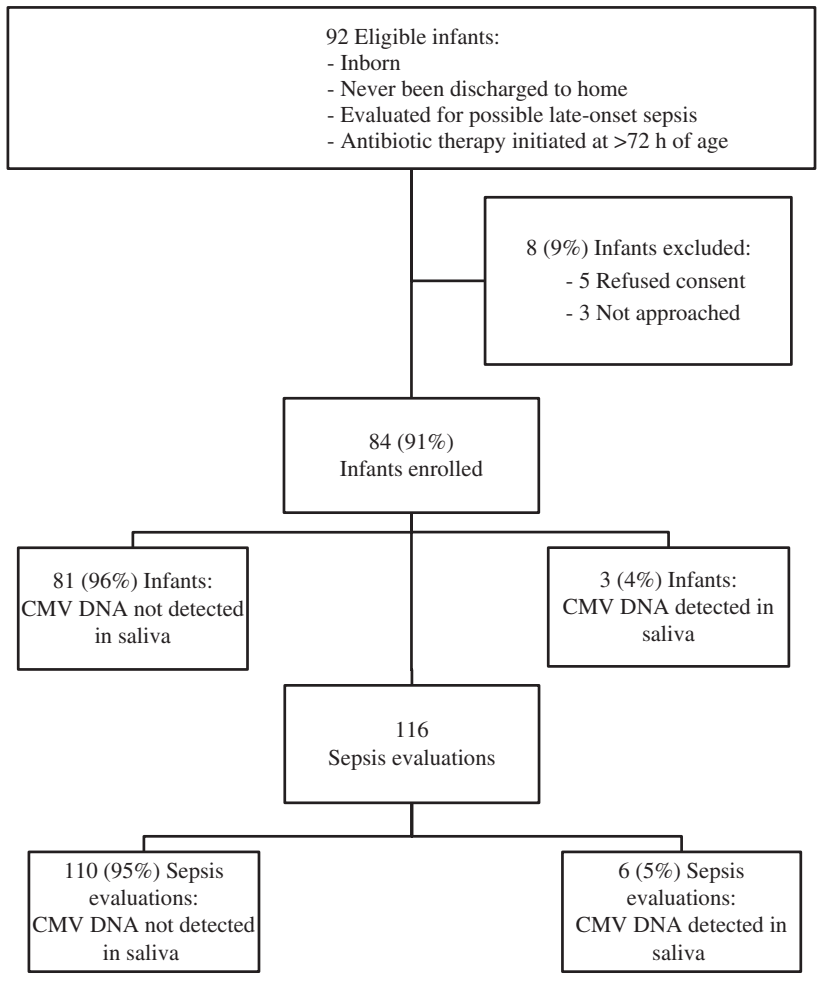

Figure 1: Study population of inborn infants in the neonatal intensive care unit who had saliva CMV DNA PCR testing performed when evaluated for possible late-onset sepsis with initiation of antibiotic therapy at $>72 \mathrm{~h}$ of age.

Table 1: Characteristics of the 84 mothers and the enrolled infants.

\begin{tabular}{lr}
\hline No. of mothers & $\mathbf{8 4}$ \\
\hline Age, year; mean \pm SD, range & $29 \pm 7.5(14-44)$ \\
Race/ethnicity & $68(81 \%)$ \\
$\quad$ Hispanic & $14(17 \%)$ \\
Black & $2(2 \%)$ \\
$\quad$ White & \\
Type of delivery & $27(32 \%)$ \\
$\quad$ Vaginal & $57(68 \%)$ \\
Cesarean section & 84 \\
\hline No. of infants & $29.5(27-36)$ \\
\hline Gestational age, week; median, IQR & $1380(900-2236)$ \\
Weight, g; median, IQR & $51(60.7 \%)$ \\
Male gender & $18(9-38)$ \\
Age at sepsis evaluation, days, median, IQR & $65(36-95)$ \\
Duration of hospitalization, days; median, IQR &
\end{tabular}

SD, standard deviation; IQR, interquartile range.

of possible infection occurred at a median age of 18 days and the median duration of hospitalization was 65 days. The 84 infants received 116 evaluations for possible sepsis with initiation of antimicrobial therapy; 21 of them had two sepsis evaluations, eight had three and three had four performed. A saliva swab was collected at $112(97 \%)$ sepsis evaluations.

Three (4\%) of the 84 infants, representing six (5\%) of the 116 sepsis evaluations, had CMV detected from the saliva swab (Figures 1 and 2; Tables 2 and 3). The clinical signs that prompted the sepsis evaluation in these three infants included hypothermia $(n=4)$, fever $(n=2)$, tachypnea $(n=6)$ and apnea $(n=1)$. Two of the three infants (Patients \#2, 3; Table 3, Figure 2) had negative saliva CMV PCR tests before 21 days of age (Patient \#2, 17 days of age; \#3, 4 and 14 days of age; Table 3, Figure 2) before testing positive for CMV DNA at 85 and 27 days of age, respectively. Patient \#2 was small for gestational age (SGA) and had received maternal milk before testing positive for CMV in saliva. Patient \#3 did not receive maternal milk but was transfused with packed red blood cells four times and platelets twice before testing positive for CMV DNA in saliva at 27 days of age. For clinical reasons unrelated to the study (thrombocytopenia), Patient \#3 also had a negative CMV urine culture 6 days before and 8 and 25 days after testing positive for CMV DNA in saliva specimen. On the other hand, Patient \#1 (Table 3, Figure 2) with gastroschisis was evaluated for sepsis four times and the saliva CMV DNA PCR test was positive in each evaluation (37, 52, 100 and 120 days of age) with increasing CMV viral load from the first to the third evaluation. Patients 2 and 3 developed severe BPD, while none were diagnosed with pneumonia, necrotizing enterocolitis or hearing loss. None of the infants received antiviral therapy, and all the three infants survived to NICU discharge.

Overall, the main reasons for the sepsis evaluations were respiratory signs $(96 \%, 111 / 116)$, mainly tachypnea $(89 \%, 103 / 116)$ and chest retractions $(61 \%, 71 / 116)$, and gastrointestinal signs $(47 \%, 54 / 116)$, principally feeding intolerance $(39 \%, 45 / 116)$ and abdominal distension $(28 \%$, 32/116) (Table 2). Compared to infants whose saliva CMV PCR test was negative, infants who had CMV detected in saliva swabs were older ( 37 vs. 15 days, $\mathrm{P}=0.07$ ) and had a lower platelet count $(84,000 / \mathrm{mL}$ vs. $269,000 / \mathrm{mL} ; \mathrm{P}=0.03)$ and a higher white blood cell count in the cerebrospinal fluid (247 cells/mL vs. 4 cells $/ \mathrm{mL}, \mathrm{P}=0.015$ ). None of the cerebrospinal fluids were tested for CMV by PCR or culture.

There was no difference in median duration of antibiotic therapy between CMV-positive and CMV-negative infants (3 days [IQR 2.7-9.2] vs. 5 days [IQR 2-7], respectively; $\mathrm{P}=0.84$, Table 2). Two of the three infants who had CMV detected in saliva had blood and urine cultures positive for bacteria, with one having Klebsiella oxytoca bacteremia and Enterobacter cloacae UTI (urine obtained by bladder catheterization yielded $10,000 \mathrm{CFU} / \mathrm{mL}$ ) while the 
A

\begin{tabular}{|c|c|}
\hline $\begin{array}{c}\text { DOL \#37 } \\
\text { Sepsis evaluation \#1 } \\
\text { CMV detected from saliva swab } \\
\text { Bacteremia (Klebsiella oxytoca) } \\
\text { UTI (Escherichia cloacae) } \\
\text { Respiratory viral PCR panel negative }\end{array}$ & $\begin{array}{c}\text { DOL \#100 } \\
\text { Sepsis evaluation \#3 } \\
\text { CMV detected from saliva swab } \\
\text { Bacterial cultures sterile }\end{array}$ \\
Respiratory viral PCR panel negative
\end{tabular}

B

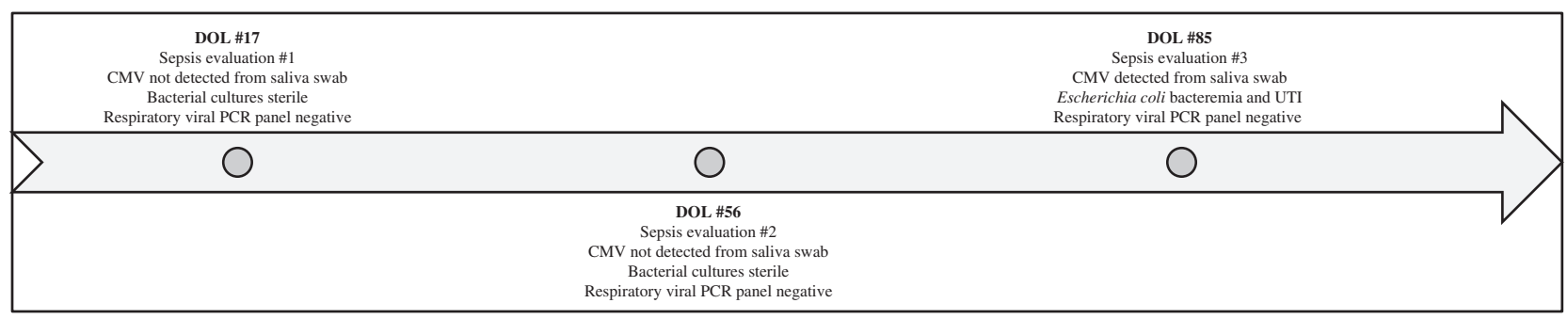

C

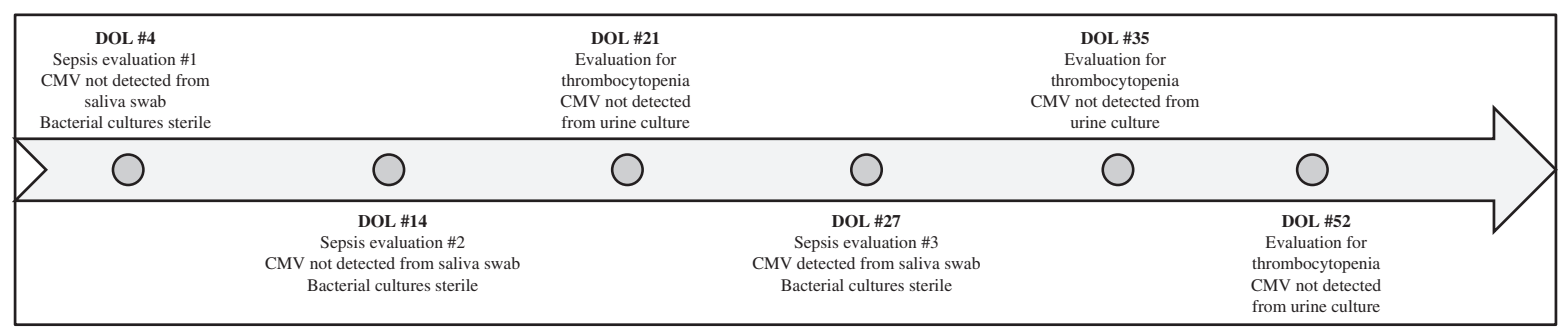

Figure 2: Event timeline of the three infants who had CMV DNA detected in saliva by PCR testing.

(A) Patient \#1 (Hispanic male; birth weight, 2760 g; gestational age, 36 weeks; gastroschisis; +maternal milk). (B) Patient \#2 (Hispanic male; birth weight, 770 g; gestational age, 27 weeks; SGA; BPD; +maternal milk). (C) Patient \#3 (Hispanic male; birth weight, 950 g; gestational age, 28 weeks; BPD; no maternal milk), CMV=Cytomegalovirus, $\mathrm{PCR}=$ polymerase chain reaction, $\mathrm{g}=$ grams, $\mathrm{DOL}=\mathrm{day}$ of life, $\mathrm{UTI}=$ urinary tract infection, $\mathrm{SGA}=$ small for gestational age, $\mathrm{BPD}=$ bronchopulmonary dysplasia.

other infant had Escherichia coli isolated from the blood and urine (urine obtained by bladder catheterization yielded 100,000 CFU/mL; Tables 2 and 3. Figure 2). The third infant did not have any bacteria isolated from any of the sepsis evaluations, and none of the three infants had a respiratory virus detected in nasopharyngeal specimens. Infants in whom CMV was detected in saliva had a significantly longer duration of hospitalization ( $117 \pm 26$ days) than infants without CMV detection $(63 \pm 38 ; \mathrm{P}=0.01$; Table 2).

\section{Discussion}

This study represents the first time that the potential role of CMV in late-onset sepsis has been evaluated in a prospective and systematic fashion. Among 84 infants in the NICU who underwent 116 sepsis evaluations with initiation of antibiotic therapy, three (4\%) infants had CMV DNA detected in saliva by PCR testing in six (5\%) sepsis evaluations. Overall, the three infants had 10 sepsis evaluations performed with one infant having CMV detected in all four sepsis evaluations (Table 3, Figure 2). Although previous studies have associated postnatal CMV detection with a severe sepsis-like syndrome [6], necrotizing enterocolitis [3, 4], BPD [1, 2] and mortality, the infants in this study mostly had temperature instability and respiratory signs. In addition, detection of CMV was associated with significantly lower platelet counts at the time of the sepsis evaluation (Table 2), and two infants developed severe BPD. While two infants also had a concomitant bacterial infection, namely bacteremia and UTI, none died.

This study highlights the problem of attributing clinical illness to detection of CMV in a clinical specimen among infants in the NICU. One of the infants had CMV 
Table 2: Characteristics of the 84 infants who had a sepsis evaluation performed at $>72 \mathrm{~h}$ of age in the neonatal intensive care unit and had a saliva specimen obtained for detection of CMV DNA by polymerase chain reaction testing.

\begin{tabular}{|c|c|c|c|}
\hline & \multicolumn{3}{|c|}{ CMV detection in saliva } \\
\hline & Yes & No & P-value \\
\hline No. of infants & $3(4 \%)$ & $81(96 \%)$ & - \\
\hline Gestational age, weeks; median, IQR & $28(28-32)$ & $30(27-36)$ & 0.79 \\
\hline Birth weight, g; median, IQR & $950(860-1855)$ & $1380(900-2223)$ & 0.61 \\
\hline Gender (male; $\mathrm{n}, \%$ ) & $3(100 \%)$ & $48(60 \%)$ & 0.27 \\
\hline Age at initial CMV detection/testing, days; median, IQR & $37(32-61)$ & $15(9-34)$ & 0.07 \\
\hline Weight at initial CMV detection/testing, g; median, IQR & $2470(1955-3018)$ & $1658(1079-2409)$ & 0.18 \\
\hline No. of sepsis evaluations & $6(5 \%)$ & $110(95 \%)$ & \\
\hline \multicolumn{4}{|l|}{ Temperature $(\mathrm{T})$ instability } \\
\hline Hypothermia $\left(\mathrm{T}<36^{\circ} \mathrm{C}\right)$ & 0 & $21(19 \%)$ & 1.0 \\
\hline Fever $\left(\mathrm{T} \geq 38^{\circ} \mathrm{C}\right)$ & $2(33 \%)$ & $7(6 \%)$ & 0.14 \\
\hline Apnea & $1(17 \%)$ & $64(58 \%)$ & 0.08 \\
\hline \multicolumn{4}{|l|}{ Respiratory signs } \\
\hline Any & $6(100 \%)$ & $105(86 \%)$ & 1.0 \\
\hline Tachypnea & $6(100 \%)$ & 97 (88\%) & 1.0 \\
\hline Retractions & $3(50 \%)$ & $68(62 \%)$ & 1.0 \\
\hline Rhinorrhea & 0 & $4(3.6 \%)$ & 1.0 \\
\hline Congestion & 0 & $2(1.8 \%)$ & 1.0 \\
\hline Cough & 0 & $3(2.7 \%)$ & 1.0 \\
\hline Increased or need for oxygen & $3(50 \%)$ & $79(72 \%)$ & 0.36 \\
\hline Maximum respiratory support & $2(33 \%)$ & $78(71 \%)$ & 0.7 \\
\hline Nasal cannula & 0 & $21(19 \%)$ & 1.0 \\
\hline CPAP & $1(17 \%)$ & $24(22 \%)$ & 1.0 \\
\hline Mechanical ventilation & $1(17 \%)$ & $33(30 \%)$ & 1.0 \\
\hline \multicolumn{4}{|l|}{ Gastrointestinal signs } \\
\hline Any & $1(17 \%)$ & $53(48 \%)$ & 0.2 \\
\hline Feeding intolerance & $1(17 \%)$ & $44(40 \%)$ & 1.0 \\
\hline Emesis & $1(17 \%)$ & $26(24 \%)$ & 1.0 \\
\hline Abdominal distension & $1(17 \%)$ & $31(28 \%)$ & 1.0 \\
\hline Hypotension & 0 & $14(13 \%)$ & 1.0 \\
\hline Fluid bolus (saline; intravenous) & 0 & $14(13 \%)$ & 1.0 \\
\hline Inotropic agents & 0 & $8(7 \%)$ & 1.0 \\
\hline \multicolumn{4}{|l|}{ Neurological signs: } \\
\hline Any & $1(17 \%)$ & $21(19 \%)$ & 1.0 \\
\hline Lethargy & $1(17 \%)$ & $13(12 \%)$ & 1.0 \\
\hline Hypotonia & $1(17 \%)$ & $9(8 \%)$ & 1.0 \\
\hline Irritability & 0 & $4(4 \%)$ & 1.0 \\
\hline \multicolumn{4}{|l|}{ Hematological values ( $1^{\text {st }}$ CMV detection) } \\
\hline White cell blood count, cells $/ \mathrm{mL}$, median, IQR & $7310(6340-14340)$ & $11,535(8410-16425)$ & 0.31 \\
\hline Absolute total neutrophils, cells/mL, median, IQR & $3140(2830-8580)$ & $4439(3267-8120)$ & 1.0 \\
\hline Lymphocytes, cells/mL, median, IQR & $3264(2482-4290)$ & $3845(2626.7-5334)$ & 1.0 \\
\hline Platelets, \#/mL, median, IQR & $84,000(34,000-224,000)$ & $269,000(172,000-387,000)$ & 0.03 \\
\hline Hemoglobin, g/dL, median, IQR & $8(8-11)$ & $11(9-13)$ & 0.36 \\
\hline Hematocrit, \%, median, IQR & $26(26-35)$ & $33(28-39)$ & 0.48 \\
\hline Cerebrospinal fluid (n): & 4 & 69 & \\
\hline Protein, $\mathrm{mg} / \mathrm{dL}$, median, IQR & $246(51-553)$ & $132(109-191)$ & 0.83 \\
\hline Glucose, $\mathrm{mg} / \mathrm{dL}$, median, IQR & $48(42-94)$ & $53(43-68)$ & 0.88 \\
\hline White blood cells, cells/mL, median, IQR & $247(28-1056)$ & $4(2-13)$ & 0.015 \\
\hline \multicolumn{4}{|l|}{ Bacterial co-infection } \\
\hline Urine culture positive & $2 / 6(33 \%)$ & $15 / 110(14 \%)$ & 0.21 \\
\hline Blood culture positive & $2 / 6(33 \%)$ & $20 / 110(18 \%)$ & 0.32 \\
\hline CLABSI & $1 / 6(17 \%)$ & $14 / 110(13 \%)$ & 0.57 \\
\hline
\end{tabular}


Table 2 (continued)

\begin{tabular}{|c|c|c|c|}
\hline & \multicolumn{3}{|c|}{ CMV detection in saliva } \\
\hline & Yes & No & P-value \\
\hline Respiratory viral infection & 0 & $8 / 110(7 \%)^{a}$ & 1 \\
\hline Antibiotic duration, days; median, IQR & $3(3-9)$ & $5(2-7)$ & 0.84 \\
\hline Hearing loss at discharge & 0 & $1 / 75(1 \%)$ & 1 \\
\hline \multicolumn{4}{|l|}{ Bronchopulmonary dysplasia } \\
\hline Any & $2(67 \%)$ & $21(26 \%)$ & 0.12 \\
\hline Mild & 0 & $10(48 \%)$ & 1.0 \\
\hline Moderate & 0 & $1(5 \%)$ & 1.0 \\
\hline Severe & $2(100 \%)$ & $13(62 \%)$ & 1.0 \\
\hline Duration of hospitalization, days, mean, SD & $117( \pm 26)$ & $63( \pm 38)$ & 0.01 \\
\hline Death & 0 & $4(4 \%)$ & 1 \\
\hline
\end{tabular}

IQR, interquartile range; CMV, cytomegalovirus; CPAP, continuous positive airway pressure; SD, standard deviation; CLABSI, central line-associated bloodstream infection. ${ }^{a}$ Enterovirus/rhinovirus, 2; rhinovirus, 2; coronaviruses, 2; parainfluenza-3 virus, 2 . In bold P-value $<0.05$.

DNA detected at $>21$ days of age during all four sepsis evaluations and the contribution of CMV to each illness is questionable (Table 3, Figure 2). It is likely that this situation represented persistent CMV shedding that is known to occur for weeks to months after initial infection [15]. Interestingly, this infant had Gram-negative bloodstream infection and UTI, and could represent reactivation of previous asymptomatic infection as in older individuals [16]. Two of the infants (Table 3, Figure 2; Patients 2, 3) had acquired CMV infection as both previously had negative saliva CMV PCR tests before 21 days of age. One of them (Table 3, Figure 2; Patient 3) had a low CMV saliva viral load at 27 days of age, and had never received maternal milk but was transfused several times. This infant had urine CMV cultures performed as part of clinical care once before and twice after the saliva PCR test was positive, raising the possibility of a false-positive PCR test. However, CMV PCR has been shown to have higher sensitivity than culture [17, 18], and it remains unknown how best to identify infants in the NICU with acquired CMV infection.

Limitations of this study include the relatively small sample size with the infrequent detection of CMV in the study patients, making associations difficult to assess. The low rate of CMV detection may be secondary to the enrollment of both term and preterm infants, as only $57 \%$ of the infants had a birth weight $<1500 \mathrm{~g}$ and presumably at a higher risk of experiencing symptomatic postnatal CMV disease. In addition, the precise mode of acquisition of CMV in the three study infants could not be ascertained with certainty as the CMV serostatus of the mothers was unknown, detection of CMV in maternal milk was not performed and detection of CMV was not performed in the first 21 days of age to exclude congenital infection in one infant. Unfortunately, the frequency of maternal milk feeding in the study population was not known although the breast feeding rate among this predominantly Hispanic population was $>90 \%$ (unpublished data). In addition, CMV testing was performed only if the infant was evaluated for sepsis and antibiotic therapy was initiated, so infants with milder clinical signs of possible infection were not identified [19]. Finally, blood CMV viral load was not performed, and this may be a better marker of acute and acquired infection. Nonetheless, how to attribute causation when CMV can be detected in multiple serial clinical specimens remains problematic.

A strength of this study is its prospective nature with enrollment of $91 \%$ of all infants with clinical signs of possible sepsis. The infrequent detection of CMV during clinical sepsis episodes suggests that its role in causing acute infection is relatively low. In a meta-analysis of studies of human milk and acquired CMV infection in preterm, very-low-birth-weight infants, Lanzieri et al. [20] reported that approximately $13-19 \%$ of infants fed fresh or frozen breast milk acquired CMV infection, but only 4-5\% developed CMV-related sepsis-like illness [20-28].

In conclusion, detection of CMV DNA in saliva occurred in $4 \%$ of infants and $5 \%$ of sepsis evaluations, suggesting that CMV is not a major contributor to lateonset sepsis in the NICU. The detection of CMV in clinical specimens is further complicated by its persistent shedding in infected infants, making attribution of disease difficult at best. Only through universal screening of all NICU admissions and development of improved biomarkers of disease causation [29] will the true impact of this infection in the NICU setting be fully understood. 


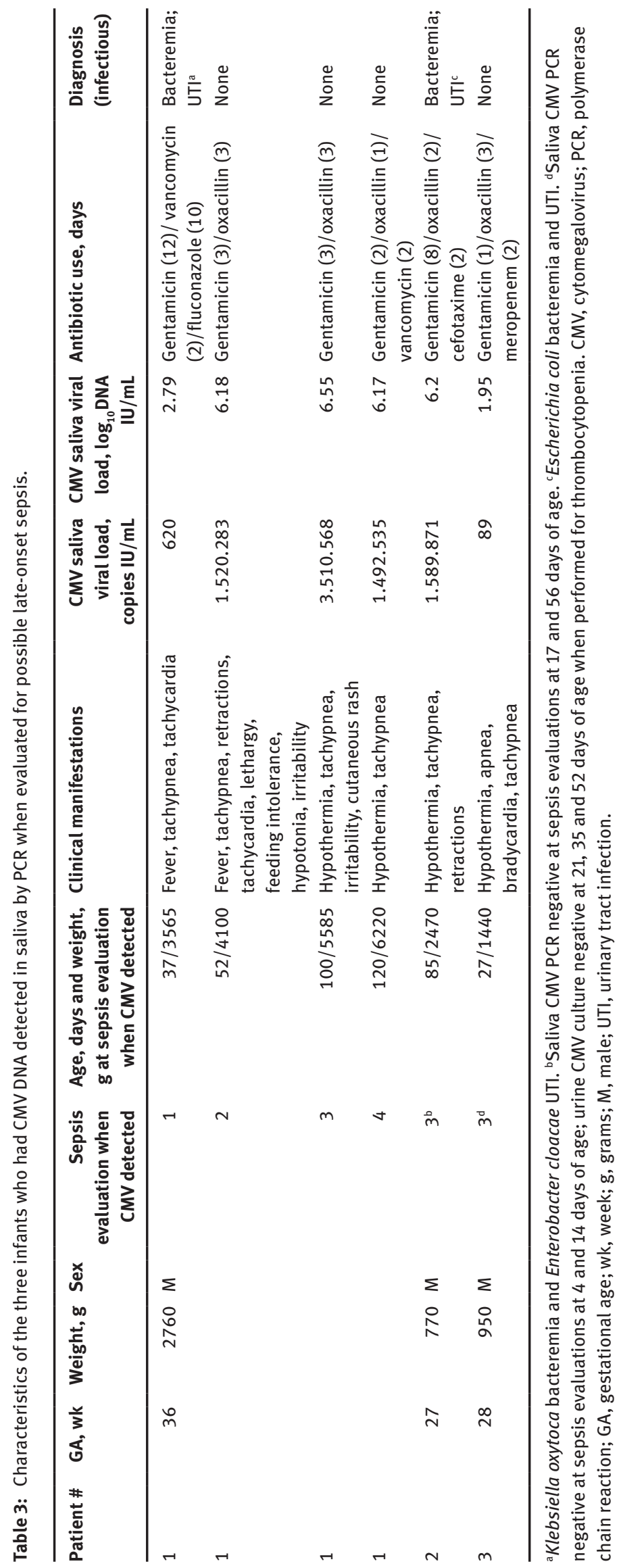

Brought to you by | Università degli Studi di Milano 
Acknowledgments: The authors thank the following employees of Parkland Memorial Hospital: John Gard, Pharm. D., Melody Bush, RPh, Sara Mureeba, Pharm. D., and Sheeba Tharayil, Pharm. D. of the NICU pharmacy for assistance with identification of study patients, Lea Maria Pereira Mendes of Language Services for support in patient recruitment and consenting and the NICU nurses for assistance with sample collection.

Author contributions: All the authors have accepted responsibility for the entire content of this submitted manuscript and approved submission.

Research funding: None declared.

Employment or leadership: None declared.

Honorarium: None declared.

Competing interests: The funding organization(s) played no role in the study design; in the collection, analysis, and interpretation of data; in the writing of the report; or in the decision to submit the report for publication.

\section{References}

1. Kelly MS, Benjamin DK, Puopolo KM, Laughon MM, Clark RH, Mukhopadhyay S, et al. Postnatal cytomegalovirus infection and the risk for bronchopulmonary dysplasia. JAMA Pediatr 2015;169:e153785.

2. Kimberlin DW. Sequelae following postnatally acquired cytomegalovirus infection in very low-birth-weight neonates: back to the future. JAMA Pediatr 2015;169:e153841.

3. Goelz R, Hamprecht K, Klingel K, Poets CF. Intestinal manifestations of postnatal and congenital cytomegalovirus infection in term and preterm infants. J Clin Virol 2016;83:29-36.

4. Tran L, Ferris M, Norori J, Stark M, Craver R, Dowd S, et al. Necrotizing enterocolitis and cytomegalovirus infection in a premature infant. Pediatrics 2013;131:e318-22.

5. Turner KM, Lee HC, Boppana SB, Carlo WA, Randolph DA. Incidence and impact of CMV infection in very low birth weight infants. Pediatrics 2014;133:e609-15.

6. Takahashi R, Tagawa M, Sanjo M, Chiba H, Ito T, Yamada M, et al. Severe postnatal cytomegalovirus infection in a very premature infant. Neonatology 2007;92:236-9.

7. Josephson CD, Caliendo AM, Easley KA, Knezevic A, Shenvi N, Hinkes MT, et al. Blood transfusion and breast milk transmission of cytomegalovirus in very low-birth-weight infants: a prospective cohort study. JAMA Pediatr 2014;168:1054-62.

8. Ronchi A, Michelow IC, Chapin KC, Bliss JM, Pugni L, Mosca F, et al. Viral respiratory tract infections in the neonatal intensive care unit: the VIRIoN-I study. J Pediatr 2014;165:690-6.

9. Delaney M, Mayock D, Knezevic A, Norby-Slycord C, Kleine E, Patel R, et al. Postnatal cytomegalovirus infection: a pilot comparative effectiveness study of transfusion safety using leukoreduced-only transfusion strategy. Transfusion 2016;56:1945-50.
10. Lunze K, Bloom DE, Jamison DT, Hamer DH. The global burden of neonatal hypothermia: systematic review of a major challenge for newborn survival. BMC Med 2013;11:24.

11. Baraff LJ. Management of infants and young children with fever without source. Pediatr Ann 2008;37:673-9.

12. Sola-Visner M, Saxonhouse MA, Brown RE. Neonatal thrombocytopenia: what we do and don't know. Early Hum Dev 2008;84:499-506.

13. Jobe AH, Bancalari E. Bronchopulmonary dysplasia. Am J Respir Crit Care Med 2001;163:1723-9.

14. Sanchez JL, Storch GA. Multiplex, quantitative, real-time PCR assay for cytomegalovirus and human DNA. J Clin Microbiol 2002;40:2381-6.

15. Rosenthal LS, Fowler KB, Boppana SB, Britt WJ, Pass RF, Schmid SD, et al. Cytomegalovirus shedding and delayed sensorineural hearing loss: results from longitudinal followup of children with congenital infection. Pediatr Infect Dis J 2009;28:515-20.

16. Sissons JG, Bain M, Wills MR. Latency and reactivation of human cytomegalovirus. J Infect 2002;44:73-7.

17. Pinninti SG, Ross SA, Shimamura M, Novak Z, Palmer AL, Ahmed $A$, et al. Comparison of saliva PCR assay versus rapid culture for detection of congenital cytomegalovirus infection. Pediatr Infect Dis J 2015;34:536-7.

18. Ross SA, Ahmed A, Palmer AL, Michaels MG, Sanchez PJ, Bernstein DI, et al. Detection of congenital cytomegalovirus infection by real-time polymerase chain reaction analysis of saliva or urine specimens. J Infect Dis 2014;210:1415-8.

19. Mukhopadhyay S, Meyer SA, Permar SR, Puopolo KM. Symptomatic postnatal cytomegalovirus testing among very lowbirth-weight infants: indications and outcomes. Am J Perinatol 2016;33:894-902.

20. Lanzieri TM, Dollard SC, Josephson CD, Schmid DS, Bialek SR. Breast milk-acquired cytomegalovirus infection and disease in VLBW and premature infants. Pediatrics 2013;131:e1937-45.

21. Lombardi G, Garofoli F, Manzoni P, Stronati M. Breast milk-acquired cytomegalovirus infection in very low birth weight infants. J Matern Neonatal Med 2012;25(Suppl. 3):57-62.

22. Okulu E, Akin IM, Atasay B, Ciftci E, Arsan S, Turmen T. Severe postnatal cytomegalovirus infection with multisystem involvement in an extremely low birth weight infant. J Perinatol 2012;32:72-4.

23. Fischer C, Meylan P, Bickle Graz M, Gudinchet F, Vaudaux B, Berger $C$, et al. Severe postnatally acquired cytomegalovirus infection presenting with colitis, pneumonitis and sepsis-like syndrome in an extremely low birthweight infant. Neonatology 2010;97:339-45.

24. Hamprecht K, Maschmann J, Jahn G, Poets CF, Goelz R. Cytomegalovirus transmission to preterm infants during lactation. J Clin Virol 2008;41:198-205.

25. Neuberger P, Hamprecht K, Vochem M, Maschmann J, Speer $\mathrm{CP}$, Jahn $\mathrm{G}$, et al. Case-control study of symptoms and neonatal outcome of human milk-transmitted cytomegalovirus infection in premature infants. J Pediatr 2006;148:326-31.

26. Vochem M, Hamprecht K, Jahn G, Speer CP. Transmission of cytomegalovirus to preterm infants through breast milk. Pediatr Infect Dis J 1998;17:53-8. 
27. Maschmann J, Hamprecht K, Dietz K, Jahn G, Speer CP. Cytomegalovirus infection of extremely low-birth weight infants via breast milk. Clin Infect Dis 2001;33:1998-2003.

28. Yasuda A, Kimura H, Hayakawa M, Ohshiro M, Kato Y, Matsuura O, et al. Evaluation of cytomegalovirus infections transmitted via breast milk in preterm infants with a real-time polymerase chain reaction assay. Pediatric 2003;111(6 Pt 1): 1333-6.
29. Heinonen S, Jartti T, Garcia C, Oliva S, Smitherman C, Anguiano $\mathrm{E}$, et al. Rhinovirus detection in symptomatic and asymptomatic children: value of host transcriptome analysis. Am J Respir Crit Care Med 2016;193:772-82.

Article note: The study was presented in part at the Pediatric Academic Societies’ Annual Meeting, Baltimore, MD, April 30-May 3, 2016. 